\title{
Inclusion of Cephalotaxus in Taxaceae: Evidence from morphology and anatomy
}

\section{Balkrishna GHIMIRE, Mi-Jin JEONG, Chunghee LEE$^{1}$ and Kweon HEO ${ }^{2 *}$}

\author{
Plant Conservation Division, Korea National Arboretum, Pocheon 11186, Korea \\ ${ }^{1}$ Gardens and Education Division, Korea National Arboretum, Pocheon 11186, Korea \\ ${ }^{2}$ Department of Applied Plant Sciences, Kangwon National University, Chuncheon 24341, Korea \\ (Received 26 January 2018; Revised 3 March 2018; Accepted 25 May 2018)
}

\begin{abstract}
The inconsistent relationship between the monogeneric family Cephalotaxaceae and Taxaceae was discussed and the possibility of merging Cephalotaxus within Taxaceae was also reviewed. Our previous reports (cladistics analysis, leaf anatomy and wood anatomy of Taxaceae s.l.) did not find a feasible reason to create a distinction between Cephalotaxus and other Taxad genera (Taxus, Pseudotaxus, Amentotaxus, Torreya and, Austrotaxus) and thus argued for a broader concept of Taxaceae with Cephalotaxus. The monophyly of Taxaceae including Cephalotaxus is described in various contemporary molecular studies, and some of them are in support of the single large family Taxaceae with six genera. Although additional comprehensive studies in the future may perhaps weaken the precise association between Cephalotaxaceae and other Taxad genera, on the basis of recent corroborations, at this moment Taxaceae should be redefined with broad circumscriptions, including Cephalotaxus.
\end{abstract}

Keywords: Cephalotaxaceae, Cephalotaxus, Taxaceae

The genus Cephalotaxus comprises about eight to eleven species and mostly distributed in China, India, Japan, Korea, Laos, Myanmar, Thailand, and Vietnam. It is generally accepted having a sole genus, Cephalotaxus, although some authors have also placed Amentotaxus in the Cephalotaxaceae (Pilger, 1926; Page, 1990), and originally Cephalotaxus was placed in the Taxaceae s.l. as well (Eichler, 1889; Van Tieghem, 1891). Previously, based on its reduced ovuliferous scales and fleshy ovulate strobili, Cephalotaxus has been included in the Taxaceae s.l. (Pilger, 1903), but after recognition of the differing origin of these features of the female reproductive structure, the genus is elevated to its own family Cephalotaxaceae (Hart, 1987; Price, 1990; Chaw et al., 1997; Cheng et al., 2000). The fleshy structure in Cephalotaxus is the outer layer of the integument of the ovule (Singh, 1961). Due to lack of sufficient fossil record, the ancestry of the genus is still unclear (Miller, 1977). Cephalotaxus differs from Taxaceae s.s. in having its young ovules borne in pairs along a cone axis (Price, 1990). The family is also elevated to the rank of its own order Cephalotaxales by some authors (Takhtajan ex Revel, 1993; Semikhov et al., 2001).

The pollen strobilus of Amentotaxus lacks bracts but otherwise strongly resembles the compound arrangement of pollen strobilus of Cephalotaxus. Keng (1969) and Wilde (1975) believed that Amentotaxus is a link between Taxaceae s.s. and Cephalotaxus. In addition, Amentotaxus and Torreya share some anatomical features with Cephalotaxus due to which Hu and Wang (1989) assumed that Amentotaxus and Torreya are the closest relatives of Cephalotaxus. However, Chaw et al. (1995, 1997), from their studies on nuclear 18S rRNA sequences, suggested that Amentotaxus is closer to Torreya than to Cephalotaxus and better to be in Taxaceae s.s. Similar relationship has been retained by Cheng et al. (2000) on the basis of nuclear rDNA internal transcribed spacer (nrITS) sequences.

On the basis of fossil-calibrated molecular clock estimation, the divergence of Taxus and Cephalotaxus had occurred about 200 million years ago (Won and Renner, 2006). However, Hao

\footnotetext{
*Author for correspondence: laurus@kangwon.ac.kr
} 


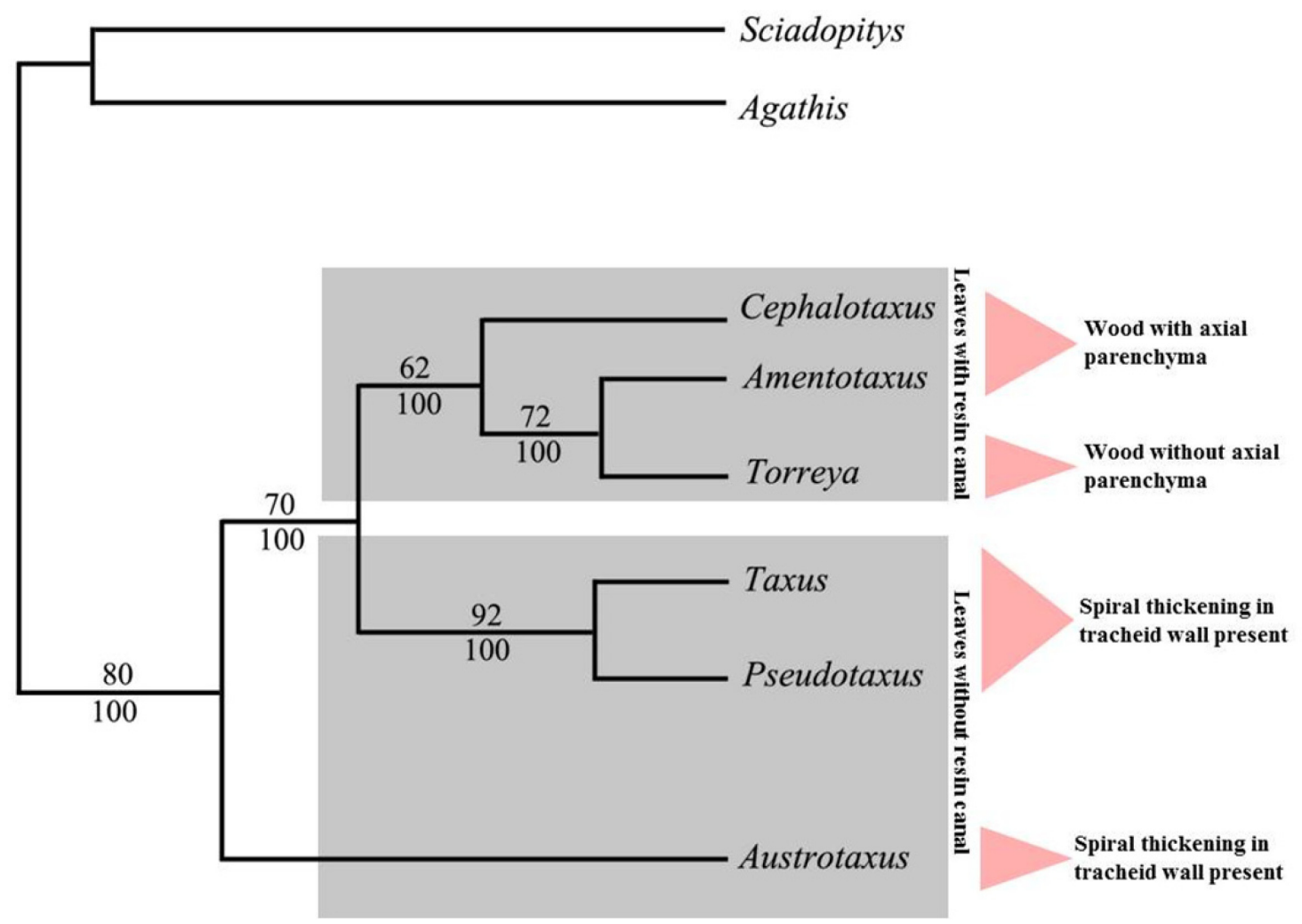

Fig. 1. Anatomical characters mapping in the semi-strict consensus tree obtained by heuristic search based on 28 morphological characters (modified from Ghimire and Heo. (2014) Plant Systematics and Evolution 300:217-223, with permission of Springer Nature).

et al. (2009) clarified that due to significant variation in constrained and unconstrained analyses such molecular clock was useless for $t r n \mathrm{~L}$ intron dataset, the $\operatorname{trn} \mathrm{L}-\mathrm{F}$ spacer, and the combined dataset. As a result, on the phylogenetic tree obtained from the portioned Bayesian analysis, maximum likelihood analysis, and maximum parsimony analysis, Hao et al. (2009) found Austrotaxus and Pseudotaxus at the base of large clad formed by Taxus and Amentotaxus + Torreya + Cephalotaxus. This result eventually favors the previous studies that Amentotaxus and Torreya are closest relatives of Cephalotaxus. Alternatively, monophyly of each taxad genera was highly supported in the most phylogenetic tree obtained from chloroplast and nuclear DNA (Cheng et al., 2000; Hao et al., 2008, 2009).

Quinn et al. (2002) have been included Cephalotaxus within Taxaceae by analyzing $r b c \mathrm{~L}$ and $m a t \mathrm{~K}$ and also stated that Taxaceae should be redefined with six genera. Before that Cheng et al. (2000) based on the analysis of chloroplast matK gene and nrITS region maintained the sister relationship between Taxaceae and Cephalotaxaceae, whereas Price (2003) suggested that Taxaceae are monophyletic when Cephalotaxus is included within it. In another study, Hao et al. (2008, 2009) supported the alternative classification of three minor families of Taxaceae, Cephalotaxaceae and Amentotaxaceae. More recently, in the new classification and linear sequence of extent gymnosperm Christenhusz et al. (2011) classified Cephalotaxus under family Taxaceae and Lu et al. (2014), on the basis of combined $L F Y$ and $N Y L$ coding sequence (CDS) sequences found the monophyly of Taxaceae s.l. including Cephalotaxus, which was consistent with the study of Leslie et al. (2012) based on $r b c \mathrm{~L}, \operatorname{mat\mathrm {K}}, 18 \mathrm{~S}$, and PHYP. However, after analyzing Cephalotaxaceae-Taxaceae lineage separately Lu et al. (2014) found weak support for Cephalotaxus within Taxaceae rather it remains sister to the group.

The above long-standing arguments and inconsistent position of Cephalotaxaceae in different analysis allow us to take a different approach to this subject. As a result, we performed cladistic analysis of Taxaceae s.l. and also compared leaf and wood anatomy of six genera of the family. This paper discussed whether it is still reasonable to classified Cephalotaxus under monotypic family Cephalotaxaceae or it's better to merge within close relative Taxaceae. The primary purpose of this paper was a collective discussion of previously published papers (Ghimire and Heo, 2014; Ghimire et al., 2014, 2015) 
to find the correct phylogenetic relationship of Taxaceae and Cephalotaxus.

\section{Morphological Features}

We reviewed 28 morphological characters of six genera of Taxaceae s.l. to resolve the problem existing in their phylogeny and to provide a new approach to their relationships. The Cephalotaxus differed from rest of Taxaceae s.l. in having compound ovulate strobili instead of simple ovulate strobili in other five genera. Nevertheless, Austrotaxus displayed more unique features than other five genera for instance lack of spiral thickenings on tracheid walls and indentations on the horizontal walls of the ray parenchyma. This can be noticeably observed in the cladistics tree, as Austrotaxus splits first in the tree and more clearly separated from the rest of the genera with eight synapomorphies (Fig. 1). It can be seen that the Taxaceae s.l. even exclusive of Austrotaxus, are paraphyletic. There are three monophyletic groups representing Cephalotaxus; Torreya + Amentotaxus; and Taxus + Pseudotaxus.

\section{Leaf anatomy}

Leaf anatomical structures of six genera were very similar each other in tissue type and their arrangements. Taxus, Austrotaxus, and Pseudotaxus were without foliar resin canal, whereas Amentotaxus, Cephalotaxus, and Torreya had single foliar resin canal situated below the vascular bundle. Among the six genera, Torreya was unique with thick walled almost rounded sclerenchymatous epidermal cells. In addition, Amentotaxus and Torreya comprised of some fiber cells around the vascular bundle. The stomata were arranged in two stomatal bands separated by midvein. The Taxus species had unique stomatal structure with papillose accessory cells forming stomatic apparatus and Torreya had deep-seated stomata covered by a special filaments forming net-like structure.

\section{Wood anatomy}

All species studied had well-represented growth rings and a narrowing of tracheids in a radial direction, occurring at the end of growth rings. Similar to other morphological features, wood structures of Taxaceae s.l. were appreciably comparable. The wood of Taxaceae s.l. was different from most of the conifers in having helical thickenings in the inner wall of tracheids, although Austrotaxus lacks these structures. Both axial and radial resin canals were absent in all species. Based on the wood features, Taxus was closely related with Torreya than Amentotaxus, Austrotaxus, and Cephalotaxus. In addition, Amentotaxus and Cephalotaxus both shared similar axial parenchyma either in diffused or sparse form with the nodulated transverse wall. The wood of Austrotaxus was unique than other genera because it had no helical thickenings in tracheid walls and contains sparse axial parenchyma with the smooth transverse wall.

\section{Phylogenetic Perspective}

The distribution of character states in cladistics tree showed that the apomorphy occurs in certain genera of the family. For example, two clades Cephalotaxus + Torreya + Amentotaxus and Taxus + Pseudotaxus are differentiated by the presence of helical thickenings in tracheids (Fig. 2A). Helical thickenings on the secondary walls of axial tracheids are a prominent feature of the wood in Taxaceae s.s. and Cephalotaxus (Greguss, 1955). Apparently, they are usually absent in Austrotaxus (Greguss, 1955; Gaussen, 1979). Although according to Phillips (1941), they were reported for this genus by Prince (1938). However, this study disagrees with Prince (1938) because no such thickenings have been found in wood of Austrotaxus spicata. Correspondingly, Austrotaxus also shows plesiomorphy on indentations on horizontal wall of ray parenchyma (Fig. 2B). Among the six genera of Taxaceae s.l. only Austrotaxus does not bear indentations in the horizontal walls of ray parenchyma. These are a small notch or serrated teeth-like structures on the cell wall. Contrary, Austrotaxus share apomorphies with Taxus + Pseudotaxus clade because these three genera lack foliar resin canal (Fig. 2C). Cephalotaxus, Amentotaxus, and Torreya have foliar resin canal which is considered as a primitive feature in the gymnosperms. The Cephalotaxus differs from other taxad genera in its compound ovulate strobilus instead of a simple (Fig. 2D). Previously, Pilger $(1903,1916)$ believed that reduced ovuliferous scales and fleshy ovulate strobili of Cephalotaxus is comparable to Taxaceae s.s., but later reports (Hart, 1987; Chaw et al., 1997; Cheng et al., 2000) recognized the different origin of female reproductive structure in both groups.

The result of leaf anatomy suggested that Cephalotaxus in one hand resembles with Torreya-Amentotaxus by having resin canal and on the other hand it shares parenchymatous epidermis and similar palisade layers with Taxus-Pseudotaxus. This result is somehow similar with the previous studies in which the genus has generally resolved as either sister to TorreyaAmentotaxus clade or sometimes allied with Taxus clade (Kershaw et al., 1994; Cheng et al., 2000). Interestingly, in both cases, the cone morphology of the genus is interpreted either a consequent explanation of an ancestrally reduced axis or a retention of the plesiomorphic condition. Some molecular 


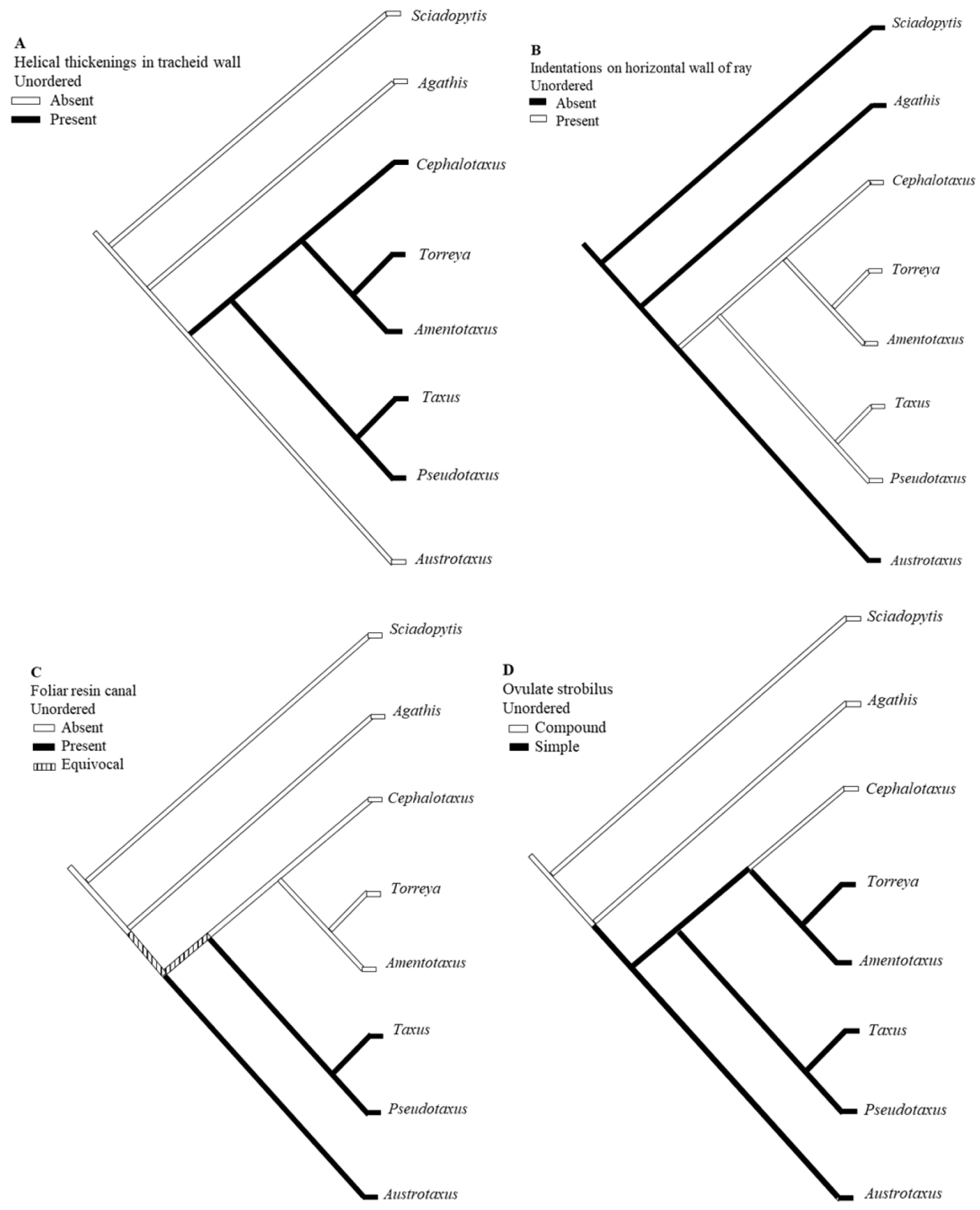

Fig. 2. Character distribution on the cladogram of Taxaceae s.l. (A, xylem wall thickenings; B, indentations on horizontal wall of ray parenchyma; $\mathbf{C}$, resin canal; and $\mathbf{D}$, ovulate strobilus).

data have also suggested that Cephalotaxus is nested within genera traditionally included in the Taxaceae (Quinn et al., 2002; Leslie et al., 2012, Lang et al., 2013). In addition, in a new classification of extent gymnosperm, Christenhusz et al.
(2011) proposed a wider concept of Taxaceae containing Cephalotaxus and all of our three reports (Ghimire and Heo, 2014; Ghimire et al., 2014, 2015) in some way came to the similar conclusion that based on the morphological features it 
is worthwhile to include Cephalotaxus within Taxaceae.

Based on the wood features, Austrotaxus was exceptional among the taxad genera because it lacks helical thickening in the tracheid wall, one of the characteristic features of Taxaceae s.l. It also had sparse axial parenchyma with completely smooth transverse walls. These are the features signifying that Austrotaxus is different from the rest of the taxad genera and thus exist in the basal position in the cladistics tree (Fig. 1). Cephalotaxus resembles Amentotaxus in having diffuse axial parenchyma with nodulated transverse walls, although Amentotaxus has parenchyma with smooth transverse walls too. The Taxus and Torreya resembled each other as the wood of both genera lack axial parenchyma. This indicated that only limited variation in wood features was observed in the five genera of Taxaceae s.l.; in fact, the explanation could be same for six genera because most of the wood features of the monotypic genus Pseudotaxus closely resemble taxad genera, particularly Taxus.

The cladistic analysis, leaf anatomy, and wood anatomy neither strongly support the Janchen's (1949) two tribe concept within Taxaceae s.s. nor of monogeneric family Cephalotaxaceae. The wider concept of Taxaceae including Cephalotaxus has already been suggested by Quinn et al. (2002) and Christenhusz et al. (2011). Furthermore, the monophyly of Taxaceae s.l. including Cephalotaxus is also reported in some recent molecular studies (Leslie et al., 2012; Lang et al., 2013; Lu et al., 2014). Nevertheless, in separate phylogenetic analyses of Cephalotaxaceae-Taxaceae lineage in the same study by $\mathrm{Lu}$ et al. (2014) found that Cephalotaxus is strongly supported to be sister to Taxaceae based on either $L F Y$ or $L F Y+N L Y$ CDS, but is weekly nested within Taxaceae based on NLY. Based on this fact they realized that such unpredictable relationship of Cephalotaxus with Taxaceae in the different analysis could be instigated by long branch attraction artifacts or inadequate resolution of markers and thus still some additional studies are needed to resolve the relationship between these two groups.

Before our cladistic analysis the morphological similarities of Taxaceae s.l. (including Cephalotaxaus) were discussed by Pant (2000) and Anderson and Owens (2003). In addition, the morphological transformation of the common conifer female cone into the unique "Female reproductive structures in Taxales" described by Stützel and Röwekamp (1999) which characterized the Taxaceae s.l. (including Cephalotaxaceae) and confirms the monophyly. Our initial hypothesis was to include Cephalotaxus within Taxaceae s.l. and the presented results and comparative review of the previous studies verified that hypothesis. Although additional studies are still necessary to come to the final conclusion, however, on the basis of prevailing evidence at the present time Taxaceae should be redefined with broad circumscriptions including Cephalotaxus.

\section{Conflict of Interest}

Authors declare that there is no conflict of interest.

\section{Literature Cited}

Anderson, E. D. and J. N. Owens. 2003. Analyzing the reproductive biology of Taxus: should it be included in Coniferales? Acta Horticulturae 615: 233-234.

Chaw, S.-M., H.-M. Sung, H. Long, A. Zharkikh and W.-H. Li. 1995. The phylogenetic position of the conifer genera Amentotaxus, Phyllocladus, and Nageia inferred from 18S rRNA sequences. Journal of Molecular Evolution 41: 224-230.

Chaw, S. M., A. Zharkikh, H. M. Sung, T. C. Lau and W. H. Li. 1997. Molecular phylogeny of extant gymnosperms and seed plant evolution: analysis of nuclear 18S rRNA sequences. Molecular Biology and Evolution 14: 56-68.

Cheng, Y., R. G. Nicolson, K. Tripp and S.-M. Chaw. 2000. Phylogeny of Taxaceae and Cephalotaxaceae genera inferred from chloroplast matK gene and nuclear rDNA ITS region. Molecular Phylogenetic and Evolution 14: 353-365.

Christenhusz, M. J. M., J. L. Reveal, A. Farjon, M. F. Gardner, R. R. Mill and M. W. Chase. 2011. A new classification and linear sequence of extant gymnosperms. Phytotaxa 19: 55-70.

Eichler, A. W. 1889. Coniferae. In Die Naturlichen Pflanzenfamilien. Vol. 1. Engler, A. and K. Prantl (eds.), Engelmann, Leipzig. Pp. 28-116.

Gaussen, H. 1979. Les Gymnospermes actuelles et fossiles. Fascicule 15. Chapitre 23-25. Les Taxines. Travaux du Laboratoire forestier de Toulouse, tome II 1: 1-24, 1-9, 1-82.

Ghimire, B. and K. Heo. 2014. Cladistic analysis of Taxaceae s.l. Plant Systematics and Evolution 300: 217-223.

Ghimire, B., C. Lee and K. Heo. 2014. Leaf anatomy and its implication for phylogenetic relationship in Taxaceae s.l. Journal of Plant Research 127: 373-388.

Ghimire, B., C. Lee and K. Heo. 2015. Comparative wood anatomy of Taxaceae. Australian Systematic Botany 28: 160-172.

Greguss, P. 1955. Identification of Living Gymnosperms on the Basis of Xylotomy. Akad Kiado, Budapest, 263 pp (Taxaceae, 147, 148, 150-157, pls, 73, 78-89).

Hao, D. C., B. L. Huang, S. L. Chen and J. Mu. 2009. Evolution of the chloroplast $t r n \mathrm{~L}-t r n \mathrm{~F}$ region in the gymnosperm lineages Taxaceae and Cephalotaxaceae. Biochemical Genetics 47: 351-369.

Hao, D. C., P. G. Xiao, B. Huang, G. B. Ge and L. Yang. 2008. 
Interspecific relationships and origin of Taxaceae and Cephalotaxaceae revealed by partitioned Bayesian analyses of chloroplast and nuclear DNA sequences. Plant Systematics and Evolution 276: 89-104.

Hart, J. A. 1987. A cladistic analysis of conifers: Preliminary results. Journal of Arnold Arboretum 68: 269-307.

Hu, Y. S. and F. H. Wang. 1989. Anatomy and affinities of Cephalotaxus (Cephalotaxaceae). Cathaya 1: 37-48.

Janchen, E. 1949. Das system der Koniferen. Osterr. Akad. Wiss. Math.-Naturwiss. K1 Sitzungsber. Abteilung 158: 155-262.

Keng, H. 1969. Aspect of morphology of Amentotaxus formosana with a note on the taxonomic position of the genus. Journal of Arnold Arboretum 50: 432-448.

Kershaw, A. P., H. A. Martin and J. R. C. McEwen Mason. 1994. The neogene: a period of transition. In History of the Australian Vegetation: Cretaceous to Recent. Hill, R. S. (ed.), Cambridge University Press, Cambridge. Pp. 299-327.

Lang, X.-D., J.-R. Su, S.-G. Lu and Z.-J. Zhang. 2013. A taxonomic revision of the genus Cephalotaxus (Taxaceae). Phytotaxa 84: 1-24.

Leslie, A. B., J. M. Beaulieu, H. S. Rai, P. R. Carne, M. J. Donoghue and S. Mathews. 2012. Hemisphere-scale differences in conifer evolutionary dynamics. Proceedings of the National Academy of Sciences of the United States of America 109: 16217-16221.

Lu, Y., J.-H. Ran, D.-M. Guo, Z.-Y. Yang and X.-Q. Wang. 2014. Phylogeny and divergence times of gymnosperms inferred from single-copy nuclear genes. PLOS ONE 9: e107679.

Miller, C. N. Jr. 1977. Mesozoic conifers. Botanical Review 43: 217-280.

Page, C. N. 1990. Coniferophytina. In The Families and Genera of Vascular Plants. Vol. 1. Pteridophytes and Gymnosperms. Kramer, K. U. and P. S. Green (eds.), Springer, Berlin. Pp. 279-361.

Pant, D. D. 2000. Inclusion of Taxaceae in separate order, Taxales. Current Science 79: 278-279.

Phillips, E. W. J. 1941. The identification of coniferous woods by their microscopic structure. Botanical Journal of Linnean Society $52: 259-320$.
Pilger, R. 1903. Taxaceae. In Pflanzenr 4 (Heft 18). Engler, A. and K. Prantl (eds.), Berlin. Pp. 1-124.

Pilger, R. 1916. Die Taxales. Mitteilungen der Deutschen Dendrologischen Gesellschaft 25: 1-28.

Pilger, R. 1926. Coniferae. In Nat. Pflanzenfam. Ed. 2. Vol. 13. Engler, A. \& K. Prantl (eds.), Wilhelm Engelmann, Leipzig. Pp. 99-403.

Price, R. A. 2003. Generic and familial relationship of the Taxaceae from $r b c \mathrm{~L}$ and $m a t \mathrm{~K}$ sequence comparison. Acta Horticulture 615: 235-237.

Price, R. R. 1990. The genera of Taxaceae in the southeastern United States. Journal of the Arnold Arboretum 71: 69-91.

Prince, J. B. 1938. Stem-wood in the gymnosperms. Unpublished Master Thesis, University New Brunswick, pp. 96.

Quinn, C. J., R. A. Price and P. A. Gadak. 2002. Familial concepts and relationships in the conifers based on $r b c \mathrm{~L}$ and matK sequence comparisons. Kew Bulletin 57: 513-531.

Semikhov, V. F., L. P. Arefeva, O. A. Novozhilova, A. S. Timoshchenko and D. S. Kostrikin. 2001. Systemic relationships of Podocarpales, Cephalotaxales, and Taxales based on comparative seed anatomy and biochemistry data. Biology Bulletin of the Russian Academy of Sciences 28: 459-470.

Singh, H. 1961. The life history and systematic position of Cephalotaxus drupacea Sieb. et Zucc. Phytomorphology 11: 153197.

Stützel, T. and I. Röwekamp. 1999. Female reproductive structures in Taxales. Flora 194: 145-157.

Takhtajan ex Reveal. 1993. Cephalotaxales. Phytologia 74: 175.

Van Tieghem, M. P. .1891. Structure et affinities des Cephalotaxus. Bulletin de la Société Botanique de France 38: 184190.

Wilde, M. H. 1975. A new interpretation of microsporangiate cones in Cephalotaxaceae and Taxaceae. Phytomorphology 25: 434-450.

Won, H. and S. S. Renner. 2006. Dating dispersal and radiation in the gymnosperm Gnetum (Gnetales): clock calibration when outgroup relationships are uncertain. Systematic Biology 55: 610-622. 